\title{
Germinação de sementes de urucum em função de métodos de superação de dormência e temperaturas ${ }^{1}$
}

\author{
Dayana Rotili Nunes Picolotto 2 , Josiane Vogel Cortina Theodoro², \\ Alfredo Ricieri Dias ${ }^{2}$, Gustavo de Faria Theodoro ${ }^{2}$, Charline Zaratin Alves ${ }^{2}$
}

\begin{abstract}
Germination of annatto seeds according to different methods for breaking dormancy and temperatures

Bixa orellana L. is a perennial plant known as annatto or achiote, which belongs to the Bixaceae family and is widely used in cooking, due to its properties of natural dye, whose germination is affected by its own characteristics. This study aimed at elucidating the dormancy mechanism of annatto seeds and evaluating the effect of different methods for breaking it, under different germination temperatures. The scarification methods were: chemical (with concentrated sulfuric acid and ethanol, under immersion for five minutes), physical (scarification with sand paper) and thermic (in water at $70^{\circ} \mathrm{C}$, for two minutes, and then under temperatures of $20^{\circ} \mathrm{C}, 25^{\circ} \mathrm{C}, 30^{\circ} \mathrm{C}$ and $20-30^{\circ} \mathrm{C}$, for germination). The amount of water absorbed by seeds, and percentage, first counting and germination rate, as well as hypocotyl and taproot length, were evaluated. For the seeds that did not germinate, the tetrazolium test was applied to verify their viability. It was concluded that the treatments used for dormancy breaking did not affect the annatto seeds viability. Scarification with sand paper or sulfuric acid, for five minutes, and temperatures of $25^{\circ} \mathrm{C}$ or $20-30^{\circ} \mathrm{C}$ are recommended.
\end{abstract}

KEY-WORDS: Bixa orellana L.; mechanical scarification; soaking curve; seeds viability.

\section{INTRODUÇÃO}

Bixa orellana L., também conhecida como urucum ou urucu, é uma espécie arbustiva originária da América tropical, que vem, a cada ano, ganhando espaço no mercado agrícola mundial, sendo cultivada nos trópicos de todo o mundo (Mercadante \& Pfander 1998). Seus frutos são cápsulas ovoides, que contêm de 30 a 40 sementes (Ramalho et al. 1988, Lorenzi 1998, Cânova 2000).

O urucuzeiro possui uma característica bastante especial, que é a capacidade de produzir substân-

\section{RESUMO}

A Bixa orellana L. é uma planta perene denominada urucu ou urucum, pertencente à família Bixaceae, muito utilizada na culinária, devido às suas propriedades de corante natural, cuja germinação é dificultada, devido às suas características próprias. Objetivou-se elucidar o mecanismo de dormência das sementes de urucum e avaliar o efeito de diferentes métodos para a sua quebra, aliados a diferentes temperaturas para a germinação. Os mecanismos de escarificação utilizados foram: químico (com ácido sulfúrico concentrado e etanol, em imersão por cinco minutos), físico (escarificação com lixa) e térmico (em água a $70^{\circ} \mathrm{C}$, por dois minutos, e, em seguida, sob temperaturas de $20^{\circ} \mathrm{C}, 25^{\circ} \mathrm{C}, 30^{\circ} \mathrm{C}$ e $20-30^{\circ} \mathrm{C}$, para germinação). Avaliou-se a quantidade de água embebida pelas sementes e percentagem, primeira contagem e índice de velocidade de germinação, assim como o comprimento do hipocótilo e da raiz principal. Para as sementes que não germinaram, aplicou-se o teste de tetrazólio, para verificar a sua viabilidade. Concluiu-se que os tratamentos utilizados para a quebra da dormência não afetaram a viabilidade das sementes de urucum. Recomenda-se a escarificação com lixa ou ácido sulfúrico, por cinco minutos, e as temperaturas de $25^{\circ} \mathrm{C}$ ou $20-30^{\circ} \mathrm{C}$.

PALAVRAS-CHAVE: Bixa orellana L.; escarificação mecânica; curva de embebição; viabilidade de sementes.

cias corantes, sendo um dos poucos permitidos pela Organização Mundial de Saúde, devido a fatores como ausência de toxicidade, além da indicação como agente hipolipidêmico (Ramalho et al. 1988, Silva et al. 2006). Contudo, o aumento na produção é consequência da expansão das áreas cultivadas e não da melhoria no rendimento, pois a propagação por sementes apresenta problemas, devido à baixa germinação das sementes (Ramalho et al. 1987, Mello \& Eira 1995).

A propagação da espécie ocorre, em geral, por sementes, que é um procedimento mais eco-

1. Trabalho recebido em dez./2012 e aceito para publicação em jul./2013 (n registro: PAT 21824).

2. Universidade Federal de Mato Grosso do Sul (UFMS), Departamento de Agronomia, Chapadão do Sul, MS, Brasil. E-mails: rnpday@yahoo.com.br, josiane.theodoro@ufms.br, alfredo@fundacaochapadao.com.br, gustavo.theodoro@ufms.br, charline.alves@ufms.br. 
nômico e fácil do que a propagação vegetativa, ou micropropagação (Pereira 1995), podendo ocorrer em sementeiras, por meio da semeadura direta, ou em sacos plásticos, cujos frutos devem ser colhidos em seu estádio mais avançado de maturação e as sementes secas à sombra, para que tenham alto poder germinativo (Ramalho et al. 1988).

Quando uma semente viável é submetida a condições favoráveis para a sua germinação e não germina, diz-se que esta se encontra em estado de dormência (Popinigis 1985), a qual pode ser dividida em embrionária, devido à presença de inibidores de germinação, e extraembrionária, na qual as estruturas que envolvem o embrião (tegumento, pericarpo, endosperma e remanescentes de órgãos florais) exercem alguma resistência física, que o mesmo não consegue superar (Bewley \& Black 1994). Os fatores que determinam este fenômeno são: embrião rudimentar ou imaturo, impermeabilidade ao oxigênio e à água, embrião dormente, restrições mecânicas e presença de substâncias inibidoras (Fowler \& Bianchetti 2000).

Para estabelecer o nível de qualidade das sementes, um dos meios utilizados é o teste de germinação, o qual é realizado em condições de substrato e temperatura ideais, para cada espécie. A temperatura tem ampla influência no processo germinativo, não apenas com relação à velocidade, mas, também, à percentagem de germinação das sementes (Carvalho \& Nakagawa 2000). Nas Regras para Análise de Sementes (Brasil 2009), são fornecidas, para as sementes da maioria das espécies, informações para a condução deste teste. No entanto, não há recomendações para sementes de urucum.

Durante o desenvolvimento das sementes de urucum, o tegumento interno se espessa, apresentando conformação estrutural e fisiológica que dificultam, em torno de $30 \%$, a germinação em ambientes naturais (Harder et al. 2007). Assim, visando a contribuir para o avanço na produção do urucuzeiro, este trabalho objetivou elucidar o mecanismo de dormência de sementes de urucum, avaliando o efeito de diferentes métodos para a superação da dormência, aliados a diferentes temperaturas para germinação.

\section{MATERIAL E MÉTODOS}

O trabalho foi conduzido no laboratório de Tecnologia de Sementes da Universidade Federal de Mato Grosso do Sul, Campus de Chapadão do Sul (MS), de setembro a novembro de 2012, sendo utilizadas sementes maduras de urucum colhidas de plantas matrizes da região.

A absorção de água pelas sementes foi estimada por meio da curva de embebição, sendo considerado o aumento de massa, após a embebição das sementes sob períodos de imersão de $0,3,6,9,12$ e 24 horas. Para cada repetição, foram colocadas 25 sementes em $100 \mathrm{~mL}$ de água destilada, com quatro repetições para cada tratamento. A diferença entre a massa fresca inicial e final (após a embebição) foi determinada em balança analítica.

Os métodos para superação da dormência foram: testemunha $\left(\mathrm{T}_{1}\right)$; escarificação mecânica com lixa grossa para madeira, até o aparecimento de coloração branca em um dos lados da semente $\left(\mathrm{T}_{2}\right)$; escarificação química com ácido sulfúrico $\left(\mathrm{H}_{2} \mathrm{SO}_{4}\right)$ concentrado $\left(\mathrm{T}_{3}\right)$, por cinco minutos, e com etanol $\left(\mathrm{T}_{4}\right)$, por cinco minutos, com agitação ocasional, sendo, as sementes, posteriormente, lavadas em água corrente; e sementes imersas em água a $70^{\circ} \mathrm{C}$, por dois minutos $\left(\mathrm{T}_{5}\right)$. Em seguida, as sementes foram postas para germinar sob temperaturas de $20^{\circ} \mathrm{C}, 25^{\circ} \mathrm{C}, 30^{\circ} \mathrm{C}$ e $20-30^{\circ} \mathrm{C}$.

O teste de germinação foi realizado em rolos de papel, com quatro repetições de 50 sementes para cada tratamento, entre três folhas de papel germitest, sendo duas utilizadas como base e uma para cobrir, umedecidas com quantidade de água destilada equivalente a 2,5 vezes a sua massa seca. Em seguida, os rolos foram envolvidos em sacos plásticos de polietileno e mantidos em germinador, sob as temperaturas descritas, e a contagem foi realizada aos 21 dias após a semeadura, computando-se as plântulas normais de cada repetição. A primeira contagem de germinação (PCG) foi realizada computando-se as plântulas normais, no décimo quarto dia após a semeadura.

Para o cálculo do índice de velocidade de germinação, foi empregada a fórmula de Maguire (1962): $\mathrm{IVG}=\mathrm{G} 1 / \mathrm{N} 1+\mathrm{G} 2 / \mathrm{N} 2+\ldots+\mathrm{Gn} / \mathrm{Nn}$, em que $\mathrm{IVG}=$ índice de velocidade de germinação; G1, G2, $\mathrm{Gn}=$ número de sementes germinadas computadas em cada contagem; e N1, N2, Nn = número de dias, em relação à data da semeadura. Aos 21 dias, foi avaliado, também, o crescimento das plântulas, por meio do comprimento do hipocótilo e da raiz principal das plântulas normais.

As sementes que não germinaram, em todos os tratamentos, foram submetidas ao teste de tetrazólio, para a avaliação da viabilidade, sendo cortadas ao meio e imersas em solução de 2, 3, 5 cloreto de 
trifeniltetrazólio a $0,075 \%$, permanecendo no escuro, a $30^{\circ} \mathrm{C}$, durante 24 horas.

O delineamento experimental foi inteiramente casualizado, em esquema fatorial $5 \times 4$ (tratamentos para superação da dormência $\mathrm{x}$ temperaturas), com quatro repetições. Os dados foram submetidos à análise da variância e as médias comparadas pelo teste Tukey, a 5\%.

\section{RESULTADOS E DISCUSSÃO}

A absorção de água pelas sementes escarificadas com ácido sulfúrico foi rápida, nas primeiras horas, seguida de um aumento lento e gradativo, e retornando, novamente, após 12 horas de embebição, a absorver água rapidamente (Figura 1). Segundo Fowler \& Bianchetti (2000) e Metivier (1986), para as sementes, normalmente, há três fases distintas na curva de embebição: uma fase inicial de rápida absorção; uma segunda fase de estabilização, em que, praticamente, não há entrada de água na semente; e uma terceira fase, em que a semente volta a ter um rápido aumento na massa fresca, como consequência da germinação.

As sementes de urucum apresentam coloração vermelha escura opaca e tegumento externo espesso, o qual é a provável causa da dormência das sementes, justamente por ser um tegumento impermeável à

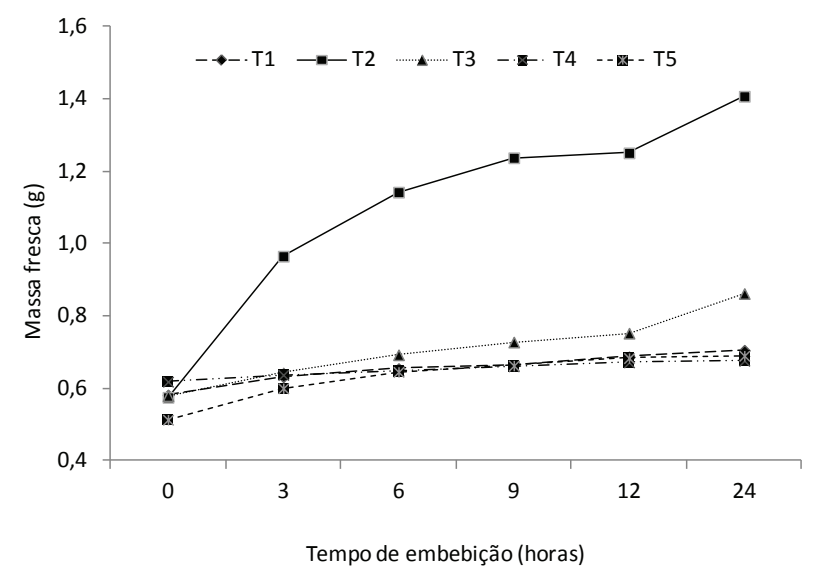

Figura 1. Curva de absorção de água por sementes de urucum intactas e escarificaradas, durante 24 horas (Chapadão do Sul, MS, 2012).

água, pois, nos tratamentos com ácido sulfúrico e lixa, este impedimento foi rompido e a semente absorveu água satisfatoriamente, corroborando os resultados obtidos por Mendes et al. (2006), que afirmam que o tegumento rígido caracteriza a dormência física, sendo esta a causa da inibição da absorção de água, em sementes intactas.

Na primeira contagem, as maiores percentagens de germinação foram obtidas nos tratamentos de escarificação com lixa, a $25^{\circ} \mathrm{C}$, e ácido sulfúrico, a $25^{\circ} \mathrm{C}$ e $30^{\circ} \mathrm{C}$ (Tabela 1 ).

Tabela 1. Primeira contagem e percentagem de germinação de sementes de urucum, em função de diferentes temperaturas e métodos para superação de dormência (Chapadão do Sul, MS, 2012).

\begin{tabular}{|c|c|c|c|c|c|}
\hline \multirow{2}{*}{$\begin{array}{c}\text { Temperaturas } \\
\left({ }^{\circ} \mathrm{C}\right)\end{array}$} & \multicolumn{5}{|c|}{ Tratamentos } \\
\hline & Testemunha & Lixa & Ácido sulfúrico & Etanol & Água quente \\
\hline & \multicolumn{5}{|c|}{ Primeira contagem de germinação (\%) } \\
\hline 20 & $1 \mathrm{bA}$ & $5 \mathrm{abD}$ & $8 \mathrm{aC}$ & $1 \mathrm{bB}$ & $1 \mathrm{bA}$ \\
\hline 25 & $2 \mathrm{cA}$ & $31 \mathrm{aA}$ & $25 \mathrm{aA}$ & $3 \mathrm{cAB}$ & $4 \mathrm{bA}$ \\
\hline 30 & $2 \mathrm{bA}$ & $26 \mathrm{aB}$ & $25 \mathrm{aA}$ & $5 \mathrm{bA}$ & $3 \mathrm{bA}$ \\
\hline $20-30$ & $3 \mathrm{bA}$ & $20 \mathrm{aC}$ & $20 \mathrm{aB}$ & $2 \mathrm{bAB}$ & $3 \mathrm{bA}$ \\
\hline \multirow[t]{2}{*}{$\mathrm{CV}(\%)$} & \multicolumn{5}{|c|}{19,6} \\
\hline & \multicolumn{5}{|c|}{ Germinação (\%) } \\
\hline 20 & $3 \mathrm{bA}$ & $17 \mathrm{aC}$ & $18 \mathrm{aB}$ & $4 \mathrm{bC}$ & $3 \mathrm{bA}$ \\
\hline 25 & $8 \mathrm{bA}$ & $63 \mathrm{aA}$ & $57 \mathrm{aA}$ & $15 \mathrm{bB}$ & $11 \mathrm{bA}$ \\
\hline 30 & $8 \mathrm{cA}$ & $52 \mathrm{aB}$ & $56 \mathrm{aA}$ & $32 \mathrm{bA}$ & $10 \mathrm{cA}$ \\
\hline $20-30$ & $8 \mathrm{bA}$ & $46 \mathrm{aB}$ & $50 \mathrm{aA}$ & $14 \mathrm{bB}$ & $7 \mathrm{bA}$ \\
\hline \multirow[t]{2}{*}{ CV $(\%)$} & \multicolumn{5}{|c|}{21,3} \\
\hline & \multicolumn{5}{|c|}{ Índice de velocidade de germinação } \\
\hline 20 & $0,2 \mathrm{cA}$ & $1,2 \mathrm{bC}$ & $1,9 \mathrm{aD}$ & $0,2 \mathrm{bcB}$ & $0,3 \mathrm{bcA}$ \\
\hline 25 & $0,6 \mathrm{bA}$ & $7,3 \mathrm{aA}$ & $7,2 \mathrm{aA}$ & $1,1 \mathrm{bAB}$ & $1,0 \mathrm{bA}$ \\
\hline 30 & $0,6 \mathrm{cA}$ & $6,8 \mathrm{aA}$ & $6,2 \mathrm{aB}$ & $1,9 \mathrm{bA}$ & $0,9 \mathrm{cA}$ \\
\hline $20-30$ & $0,7 \mathrm{bA}$ & $4,8 \mathrm{aB}$ & $5,2 \mathrm{aC}$ & $1,0 \mathrm{bAB}$ & $0,7 \mathrm{bA}$ \\
\hline CV $(\%)$ & \multicolumn{5}{|c|}{20,3} \\
\hline
\end{tabular}

Médias seguidas por letras distintas, minúsculas nas linhas e maiúsculas nas colunas, diferem entre si, pelo teste Tukey, a 5\%. 
Na última fase de maturação das sementes de urucum, há aumento na impermeabilidade do tegumento à água, que culmina em dormência imposta pelo tégmen, sendo, a partir daí, necessária uma escarificação abrasiva das sementes, para que as mesmas germinem (Amaral et al. 1995).

Para as sementes intactas, ou que passaram por processo de escarificação térmica, as diferentes temperaturas não influenciaram na primeira contagem de germinação. No entanto, para o processo de escarificação mecânica, a temperatura de $25^{\circ} \mathrm{C}$ proporcionou maiores valores de primeira contagem de germinação, assim como ocorreu na escarificação química com ácido sulfúrico, porém, neste caso, não diferiu estatisticamente da temperatura de $30^{\circ} \mathrm{C}$. Para as sementes escarificadas com etanol, a temperatura de $30^{\circ} \mathrm{C}$ se mostrou mais eficiente, diferindo, contudo, das temperaturas de $25^{\circ} \mathrm{C}$ e $20-30^{\circ} \mathrm{C}$.

Os tratamentos que utilizaram ácido sulfúrico e lixa, no processo de escarificação das sementes de urucum, diferiram, estatisticamente, dos demais tratamentos, em todas as temperaturas testadas, quanto à percentagem de germinação (Tabela 2).

Para as sementes que não passaram por nenhum tratamento, ou que foram submetidas à escarificação térmica em água quente, observou-se que as diferentes temperaturas não exerceram influência na germinação das sementes de urucum.

A temperatura de $25^{\circ} \mathrm{C}$ apresentou-se mais favorável à germinação das sementes lixadas, no entanto, para as sementes escarificadas com ácido sulfúrico, a temperatura de $25^{\circ} \mathrm{C}$ não diferiu, estatisticamente, das temperaturas de $30^{\circ} \mathrm{C}$ e $20-30^{\circ} \mathrm{C}$. Para as sementes escarificadas com etanol, observou-se que a temperatura de $30^{\circ} \mathrm{C}$ diferiu das demais, sendo que a temperatura de $20^{\circ} \mathrm{C}$ foi a que apresentou a menor germinação. Estes resultados estão de acordo com Almeida et al. (1992), os quais relataram que, para a germinação da maioria das variedades de urucum, as temperaturas de $25^{\circ} \mathrm{C}$ e $30^{\circ} \mathrm{C}$ são mais eficientes.

Lima et al. (2007) também verificaram, em sementes de urucum, maiores médias de protusão de raiz primária de sementes escarificadas a $25^{\circ} \mathrm{C}$ e $30^{\circ} \mathrm{C}$, porém, não diferindo, estatisticamente, da temperatura alternada de $20-30^{\circ} \mathrm{C}$.

Por meio do índice de velocidade de germinação (IVG), foi possível observar que, para as sementes escarificadas com lixa, quando submetidas a $25^{\circ} \mathrm{C}$ e $30^{\circ} \mathrm{C}$, houve maior vigor, pois diferiram, estatisticamente, das temperaturas de $20^{\circ} \mathrm{C}$ e $20-30^{\circ} \mathrm{C}$ (Tabela 1). Já para as sementes escarificadas com $\mathrm{H}_{2} \mathrm{SO}$, a temperatura de $25^{\circ} \mathrm{C}$ mostrou-se, estatisticamente, diferente das demais temperaturas. No entanto, para a escarificação com etanol, apenas as sementes mantidas a $30^{\circ} \mathrm{C}$ não diferiram, estatisticamente, das temperaturas de $25^{\circ} \mathrm{C}$ e $20-30^{\circ} \mathrm{C}$.

Para as sementes que não passaram por nenhum tratamento, ou que foram submetidas à escarificação térmica em água quente, verificou-se que as diferentes temperaturas não influenciaram no índice de velocidade de germinação.

A germinação é influenciada pela temperatura, existindo uma temperatura ótima, na qual se verifica máxima velocidade e percentagem de germinação, acima ou abaixo da qual a germinação é prejudicada (Carvalho \& Nakagawa 2000). A temperatura de

Tabela 2. Índice de velocidade de germinação e comprimento de hipocótilo de plântulas de urucum, em função de diferentes temperaturas e métodos para superação de dormência (Chapadão do Sul, MS, 2012).

\begin{tabular}{|c|c|c|c|c|c|}
\hline \multirow{2}{*}{$\begin{array}{c}\text { Temperaturas } \\
\left({ }^{\circ} \mathrm{C}\right) \\
\end{array}$} & \multicolumn{5}{|c|}{ Tratamentos } \\
\hline & Testemunha & Lixa & Ácido sulfúrico & Etanol & Água quente \\
\hline & \multicolumn{5}{|c|}{ Comprimento de hipocótilo $(\mathrm{cm})$} \\
\hline 20 & $0,00 \mathrm{bB}$ & $2,31 \mathrm{abC}$ & $5,20 \mathrm{aB}$ & $1,47 \mathrm{bC}$ & $0,00 \mathrm{bB}$ \\
\hline 25 & $3,69 \mathrm{cA}$ & $7,79 \mathrm{abAB}$ & $8,86 \mathrm{aA}$ & $4,98 \mathrm{bcAB}$ & $4,91 \mathrm{bcA}$ \\
\hline 30 & $4,15 \mathrm{bcA}$ & $8,68 \mathrm{aA}$ & $6,57 \mathrm{abAB}$ & $7,59 \mathrm{aA}$ & $2,77 \mathrm{cAB}$ \\
\hline $20-30$ & $4,71 \mathrm{aA}$ & $5,37 \mathrm{aB}$ & $5,08 \mathrm{aB}$ & $2,60 \mathrm{aBC}$ & $4,89 \mathrm{aA}$ \\
\hline \multirow[t]{2}{*}{ CV (\%) } & \multicolumn{5}{|c|}{34,0} \\
\hline & \multicolumn{5}{|c|}{ Comprimento de raiz (cm) } \\
\hline 20 & $0,00 \mathrm{aB}$ & $1,24 \mathrm{aB}$ & $2,95 \mathrm{aA}$ & $1,08 \mathrm{aB}$ & $0,00 \mathrm{aB}$ \\
\hline 25 & $4,68 \mathrm{aA}$ & $5,32 \mathrm{aA}$ & $3,36 \mathrm{aA}$ & $3,60 \mathrm{aAB}$ & $2,63 \mathrm{aAB}$ \\
\hline 30 & $3,55 \mathrm{abA}$ & $6,43 \mathrm{aA}$ & $4,91 \mathrm{abA}$ & $5,93 \mathrm{aA}$ & $2,70 \mathrm{bAB}$ \\
\hline $20-30$ & $6,27 \mathrm{aA}$ & $6,33 \mathrm{aA}$ & $5,37 \mathrm{aA}$ & $2,75 \mathrm{bB}$ & $5,38 \mathrm{aA}$ \\
\hline CV (\%) & & & 41,4 & & \\
\hline
\end{tabular}

Médias seguidas por letras distintas, minúsculas nas linhas e maiúsculas nas colunas, diferem entre si, pelo teste Tukey, a 5\%. 
$20^{\circ} \mathrm{C}$ afetou, na maioria dos tratamentos, o índice de velocidade de germinação de sementes de urucum, retardando o processo. Segundo Bewley \& Black (1994), este fato ocorre devido à redução das atividades enzimáticas envolvidas no metabolismo da semente.

Quanto ao comprimento de hipocótilo $(\mathrm{cm}) \mathrm{de}$ plântulas de urucum (Tabela 2), para a temperatura alternada de $20-30^{\circ} \mathrm{C}$, não houve diferença estatística entre os tratamentos. A temperatura de $30^{\circ} \mathrm{C}$ não diferiu, estatisticamente, para o comprimento do hipocótilo, nos tratamentos de escarificação mecânica e escarificação química com ácido sulfúrico concentrado e etanol. A temperatura de $20^{\circ} \mathrm{C}$ não se mostrou adequada ao desenvolvimento das plântulas de urucum. Estes dados estão de acordo com Lima et al. (2007), que demonstraram que o desenvolvimento de urucum a $20^{\circ} \mathrm{C}$ é prejudicado, apresentando maior quantidade de plântulas anormais.

Em todos os tratamentos de quebra de dormência, as temperaturas de $25^{\circ} \mathrm{C}$ e $30^{\circ} \mathrm{C}$ apresentaram as maiores médias de comprimento do hipocótilo, porém, não houve diferença entre os tratamentos com escarificação mecânica a $25^{\circ} \mathrm{C}$ e $20-30^{\circ} \mathrm{C}$, ácido sulfúrico a $30^{\circ} \mathrm{C}, 20^{\circ} \mathrm{C}$ e $20-30^{\circ} \mathrm{C}$, etanol a $25^{\circ} \mathrm{C}$ e $20-30^{\circ} \mathrm{C}$ e água quente a $30^{\circ} \mathrm{C}$ e $20^{\circ} \mathrm{C}$.

Quanto ao comprimento de raiz (Tabela 2), não houve diferença entre os tratamentos, para as temperaturas de $20^{\circ} \mathrm{C}$ e $25^{\circ} \mathrm{C}$. Já a $30^{\circ} \mathrm{C}$, os tratamentos que proporcionaram maior comprimento de raiz foram a escarificação mecânica com lixa e com etanol, não diferindo, no entanto, da testemunha e do tratamento com ácido sulfúrico. Para a temperatura alternada, não houve diferença entre os tratamentos, com exceção do etanol, que apresentou os menores valores absolutos.

No tratamento com escarificação térmica, o comprimento da raiz de plântulas de urucum foi maior a $20-30^{\circ} \mathrm{C}$, porém, não diferiu das temperaturas de $25^{\circ} \mathrm{C}$ e $30^{\circ} \mathrm{C}$, que, por sua vez, não diferiram, estatisticamente, da temperatura de $20^{\circ} \mathrm{C}$. Para o tratamento com ácido sulfúrico, não houve diferença estatística entre as temperaturas, quanto ao comprimento da raíz do urucum. Já para a testemunha e a escarificação com lixa, somente a testemunha diferiu, estatisticamente, dos demais tratamentos. No tratamento com etanol, a temperatura de $30^{\circ} \mathrm{C}$ proporcionou maior comprimento de raiz, porém, não diferiu da temperatura de $25^{\circ} \mathrm{C}$, a qual, por sua vez, não diferiu das demais temperaturas.
Além de afetar a germinação, alterações na temperatura podem provocar redução no crescimento das plântulas. Os resultados obtidos para o crescimento de hipocótilo e raiz de urucum corroboram os observados por Taiz \& Zeiger (2004) e Santos \& Zonetti (2009), os quais concluíram que o crescimento de plântulas é comprometido, quando a semente é submetida a um grau moderado de estresse térmico, podendo provocar diminuição nas atividades enzimáticas e/ou diminuição na absorção de água.

Os tratamentos utilizados para quebra de dormência das sementes de urucum não afetaram a viabilidade das mesmas (Figura 2). Já para as diferentes temperaturas de germinação, a viabilidade das sementes foi afetada de forma significativa (Figura 3), sendo que a maior média de sementes viáveis foi observada à temperatura alternada de $20-30^{\circ} \mathrm{C}$, não diferindo, estatisticamente, da temperatura de $25^{\circ} \mathrm{C}$.

Esses resultados assemelham-se aos observados por Amaral et al. (1995), os quais demonstraram que

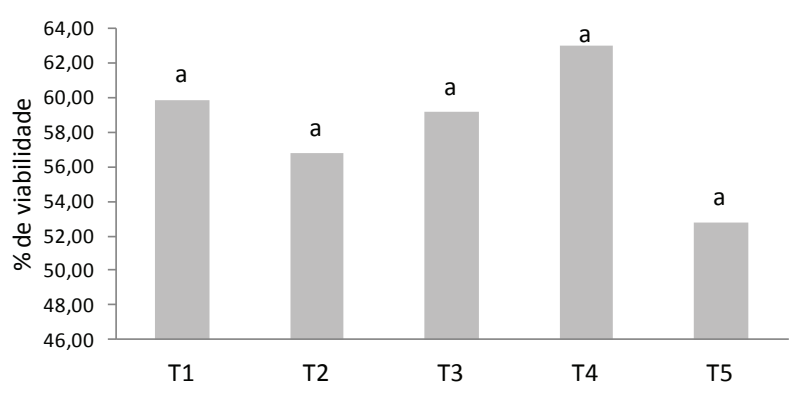

Figura 2. Efeito dos tratamentos de superação de dormência na viabilidade de sementes de urucum (Chapadão do Sul, MS, 2012). T1: sementes intactas; T2: escarificação mecânica; T3: escarificação química (ácido sulfúrico); T4: etanol; T5: escarificação térmica.

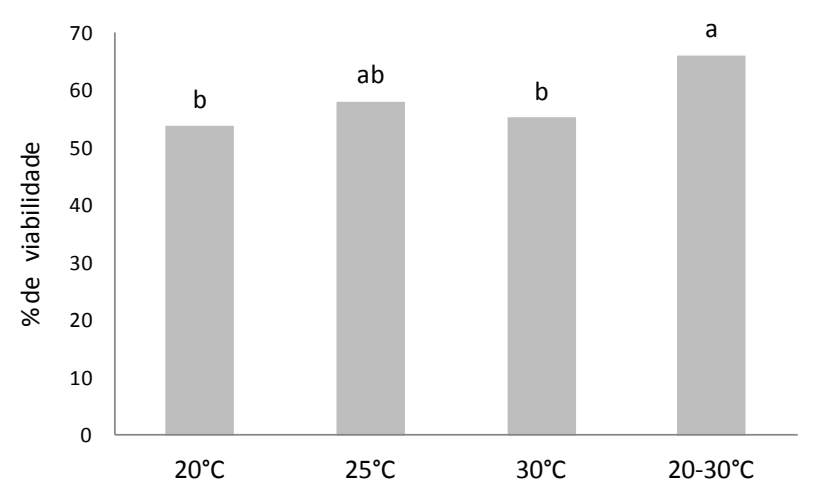

Figura 3. Efeito de diferentes temperaturas na viabilidade de sementes de urucum (Chapadão do Sul, MS, 2012). 
as sementes de urucum requerem, para a germinação, alternância periódica de temperatura. Goldbach (1979) relatou que, entre $25^{\circ} \mathrm{C}$ e $30^{\circ} \mathrm{C}$, ocorre o maior índice de sementes viáveis de urucum, e Almeida et al. (1992) descreveram que, entre 10 variedades de urucum examinadas, nove apresentaram melhores índices de viabilidade entre $25^{\circ} \mathrm{C}$ e $30^{\circ} \mathrm{C}$, porém, sem conduzirem seu experimento em temperaturas alternadas.

Para espécies cujas sementes estão adaptadas a responder a flutuações térmicas, existem mecanismos enzimáticos que funcionam sob diferentes temperaturas (Vázquez-Yanes \& Orozco-Segovia 1984). Assim, a germinação ocorre adequadamente apenas quando houver variação térmica, durante o processo catalizado por estas enzimas. A alternância de temperatura age sobre o tegumento das sementes, tornando-o mais permeável à água e ao oxigênio, parecendo agir, também, sobre o equilíbrio entre as substâncias promotoras e inibidoras da germinação (Cícero 1986).

Essa alternância corresponde às flutuações naturais encontradas no ambiente e parece estar associada com a quebra da dormência. A flutuação de temperatura é um mecanismo que controla eventos de colonização no tempo e no espaço, proporcionando a quebra da dormência, onde as condições são relativamente favoráveis ao estabelecimento de plântulas de algumas espécies vegetais (Moreno-Casasola et al. 1994).

Por outro lado, a escarificação mecânica tem sido efetiva para quebrar a dormência de muitas sementes impermeáveis, pois, em muitos casos, a promoção da germinação está relacionada com a entrada de água na semente. Para as sementes de urucum, a escarificação mecânica foi efetiva na quebra da dormência e a entrada de água foi positivamente associada à escarificação. Assim, nestas sementes, a testa constituiu-se em uma barreira física ao fluxo de água.

A escarificação química promoveu a germinação, paralelamente ao aumento da permeabilidade das sementes. A viabilidade não foi afetada por este tratamento, podendo-se inferir que o ácido sulfúrico não atingiu as regiões abaixo da testa e, por isto, não causou danos ao embrião.

\section{CONCLUSÕES}

1. Os tratamentos utilizados para a quebra de dormência não afetaram a viabilidade das sementes de urucum.
2. Recomenda-se a escarificação com lixa ou ácido sulfúrico, por cinco minutos, e as temperaturas de $25^{\circ} \mathrm{C}$ ou $20-30^{\circ} \mathrm{C}$.

\section{REFERÊNCIAS}

ALMEIDA, E. C. et al. Competição germinativa da semente de dez "tipos" de urucum (Bixa orellana) submetidos a diferentes temperaturas e luminosidades. Revista Brasileira de Corantes Naturais, Viçosa, v. 1, n. 1, p. 50-53, 1992.

AMARAL, L. I. V.; PEREIRA, M. F. A.; CORTELAZZO, A. L. Quebra da dormência em sementes de Bixa orellana. Revista Brasileira de Fisiologia Vegetal, Campinas, v. 7, n. 2, p. 151-157, 1995.

BEWLEY, J. D.; BLACK, M. Seeds: physiology of development and germination. 2. ed. New York: Plenum, 1994.

BRASIL. Ministério da Agricultura, Pecuária e Abastecimento. Secretaria de Defesa Agropecuária. Regras para análise de sementes. Brasília, DF: MAPA/ ACS, 2009.

CÂNOVA, R. Urucum. 2000. Disponível em: <http:// alemdojardim.terra.com.br/alem/mai.2000>. Acesso em: 05 maio 2000.

CARVALHO, N. M.; NAKAGAWA, J. Sementes: ciência, tecnologia e produção. 4. ed. Jaboticabal: Funep, 2000.

CÍCERO, S. M. Dormência de sementes. In: SEMANA DE ATUALIZAÇÃO EM PRODUÇÃO DE SEMENTES, 1., 1986, Piracicaba. Anais... Campinas: Fundação Cargill, 1986. p. 41-73.

FOWLER, A. J. P.; BIANCHETTI, A. Dormência em sementes florestais. Colombo: Embrapa Florestas, 2000. (Documentos, 40).

GOLDBACH, H. Germination and storage of Bixa orellana seeds. Seed Science and Technology, Zürich, v. 7, n. 3, p. 399-402, 1979.

HARDER, M. N. C. et al. Structural characterization of annatto seeds (Bixa orellana) by transmission and scanning electron microscopy submitted to gamma radiation for dormancy break. In: INTERNATIONAL NUCLEAR ATOMIC CONFERENCE, 7., 2007, Santos. Proceedings... Santos: CNEN, 2007. 1 CD-ROM.

LIMA, R. V.; LOPES, J. C.; COELHO, R. I. Germinação de sementes de urucu em diferentes temperaturas e substratos. Ciência e Agrotecnologia, Lavras, v. 31, n. 4, p. 1219-1224, 2007.

LORENZI, H. Árvores brasileiras: manual de identificação e cultivo de plantas arbóreas nativas do Brasil. Nova Odessa: Plantarum, 1998. 
MAGUIRE, J. D. Speed of germination-aid in selection and evolution for seedling emergence and vigor. Crop Science, Madison, v. 2, n. 2, p. 176-177, 1962.

MELLO, C. M. C.; EIRA, M. T. S. Conservação de sementes de urucum (Bixa orellana L.). In: CONGRESSO BRASILEIRO DE SEMENTES, 9., 1995, Florianópolis. Resumos... Londrina: Abrates, 1995. p. 183.

MENDES, A. M. S.; FIGUEIREDO, A. F.; SILVA, J. F. Crescimento e maturação dos frutos e sementes de urucum. Revista Brasileira de Sementes, Londrina, v. 28, n. 1, p. 133-141, 2006.

MERCADANTE, A. Z.; PFANDER, H. Carotenoids from annatto: a review. Recent Research Developments in Agriculture and Food Chemistry, New York, v. 2, n. 1, p. 79-91, 1998.

METIVIER, J. R. Dormência e germinação. In: FERRI, M. G. (Coord.). Fisiologia vegetal. 2 ed. São Paulo: EPU, 1986.

MORENO-CASASOLA, P.; GRIME, J. P.; MARTÍNEZ, M. L. A comparative study of the flutuations in temperature and moisture supply on hard coat dormancy in seeds of coastal tropical legumes in Mexico. Journal of Tropical Ecology, Cidade do México, v. 10, n. 1, p. 67-86, 1994.

PEREIRA, T. S. Caracterização de plântulas de Bixa orellana L. - urucu (Bixaceae). Revista Brasileira de Sementes, Brasília, DF, v. 17, n. 2, p. 243-248, 1995.
POPINIGIS, F. Fisiologia da semente. 2. ed. Brasília, DF: Abrates, 1985.

RAMALHO, R. S.; PINHEIRO, A. L.; DINIZ, G. S. Informações básicas sobre a cultura e utilização do urucu (Bixa orellana L.). Informe Técnico, Viçosa, v. 59, n. 8, p. 1-22, 1987.

RAMALHO, R. S.; PINHEIRO, A. L.; DINIZ, G. S. Urucum: planta rústica e de alto rendimento. A Lavoura, Rio de Janeiro, n. 90, p. 24-31, 1988.

SANTOS, G. A.; ZONETTI, P. C. Influência da temperatura na germinação e desenvolvimento do girassol (Helianthus annuus L.). Iniciação Científica Cesumar, Maringá, v. 11, n. 1, p. 23-27, 2009.

SILVA, J. H. V. et al. Resíduo da semente de urucum (Bixa orellana L.) como corante da gema, pele, bico e ovário de poedeiras avaliado por dois métodos analíticos. Ciência e Agrotecnologia, Lavras, v. 30, n. 5, p. 988-994, 2006.

TAIZ, L.; ZEIGER, E. Fisiologia vegetal. 3. ed. Porto Alegre: Artmed, 2004.

VÁZQUEZ-YANES, C.; OROZCO-SEGOVIA, A. Fisiología ecológica de las semillas de árboles de la selva tropical. Ciência, Santo Domingo, v. 35, n. 1, p. 191-201, 1984. 